ORIGINAL ARTICLE / ARTIGO ORIGINAL

\title{
Primary health care as assessed by health professionals: comparison of the traditional model versus the Family Health Strategy
}

\author{
Avaliação da atenção primária à saúde por profissionais de saúde: \\ comparação entre modelo tradicional versus Estratégia Saúde da Família
}

Cristina Rabelo Flôr', Cláudia Di Lorenzo Oliveira', Clareci Silva Cardoso', Cleonice Ferreira Rabelo', Bernardo Luis Gontijo', Suzana Freitas de Carvalho', Pedro Messenger Caldeira Bretas', Hygor Cabral Silva', Mariana Linhares Pereira', Cristiane Menezes de Pádua',"I

\begin{abstract}
Introduction: The Family Health Strategy (FHS) should be first-contact care in the Brazilian Health System. However, Primary Health Care (PHC) still encompasses two models: the FHS and the traditional health care facilities. The expansion of the FHS has been slow and heterogeneous in many cities, rendering a comparative evaluation of key quality-related elements of PHC models crucial. Objective: To compare the performance of PHC models as perceived by health professionals. Methods: A cross-sectional study involving managers and health professionals from PHC of a medium-size city in South-eastern Brazil. Data were collected by applying the Primary Care Assessment Tool. The performance was estimated through primary health care indexes (general and partial PHCI by attributes). Univariate polytomous logistic regression was performed to compare care model performances according to their attributes. Strength of association was estimated by odds ratio with 95\% confidence interval. Results: Three managers and 81 health professionals participated in the study. The FHS had a better index rating than the traditional care model for general PHCI and for the attributes longitudinality, comprehensiveness, family focus and professional level. Conclusion: Although the FHS attained higher scores compared to the traditional model, it has not yet achieved the performance expected. This scenario points to the need for increased FHS cover and quality improvements at the existing units.
\end{abstract}

Keywords: Primary Health Care. Health Services Evaluation. Health Personnel. Brazil.

'Grupo de Pesquisas em Epidemiologia e Avaliação de Novas Tecnologias em Saúde, Universidade Federal de São João del-Rei Divinópolis (MG), Brazil

"Departamento de Farmácia Social, Universidade Federal de Minas Gerais - Belo Horizonte (MG), Brazil.

Corresponding author: Cristiane Menezes de Pádua. Departamento de Farmácia Social, Universidade Federal de Minas Gerais. Avenida Antônio Carlos, 6.627, Campus Pampulha, CEP: 31270-901, Belo Horizonte, MG, Brasil. E-mail: campadua@farmacia.ufmg.br Conflict of interests: nothing to declare - Financial support: Fundação de Amparo à Pesquisa do Estado de Minas Gerais FAPEMIG through the Programa de Pesquisa para o SUS - PPSUS (Grant number APQ-03031-10).

714

REV BRAS EPIDEMIOL OUT-DEZ 2017; 20(4): 714-726 
RESUMO: Introdução: A Estratégia de Saúde da Família (ESF) deve ser o primeiro contato do Sistema Único de Saúde (SUS). Contudo dois modelos de atenção operam concomitantemente no âmbito da Atenção Primária à Saúde (APS): a ESF e o modelo tradicional. A expansão da ESF tem sido lenta e heterogênea em muitos municípios, tornando fundamental a condução de avaliações comparativas de atributos relacionados à qualidade dos modelos da APS. Objetivo: Comparar o desempenho dos modelos de atenção da APS de acordo com a percepção dos profissionais de saúde. Métodos: Estudo transversal com gestores e profissionais de saúde da APS do município de Divinópolis, Minas Gerais. Dados foram coletados por meio do Primary Care Assessment Tool. O desempenho dos modelos foi estimado por meio do Índice de Atenção Primária à Saúde (IAPS geral e específico). Regressão logística politômica univariada foi conduzida para comparação do desempenho dos modelos da APS de acordo com os atributos. A força da associação foi estimada por meio do odds ratio com intervalo de confiança de $95 \%$. Resultados: Três gestores e 81 profissionais de saúde participaram do estudo. A ESF obteve melhor avaliação do que o modelo tradicional com relação ao IAPS geral e aos atributos vínculo, elenco de serviços, enfoque familiar e formação profissional. Conclusão: A ESF obteve escores superiores aos do modelo tradicional, entretanto ainda não atingiu o seu desempenho esperado. Esse cenário aponta para a necessidade de ampliação da cobertura da ESF e para a melhoria da qualidade das unidades de ESF existentes no Brasil.

Palavras-chave: Atenção Primária à Saúde. Avaliação dos Serviços de Saúde. Profissionais de Saúde. Brasil.

\section{INTRODUCTION}

The Brazilian Health System (Sistema Único de Saúde - SUS) was created in 1988 under the Federal Constitution and has since been reformed to consolidate public health care throughout the country. In this scenario, strengthening Primary Health Care (PHC) represented the main strategy to improve the quality and quantity of health care provided by the State, assuring the principles guiding the SUS.

The Family Health Program (FHP) was conceived in 1994 and in 2009 was adopted by government as a national model called the Family Health Strategy (FHS) to reorganize PHC nationwide ${ }^{1-3}$. Since then the FHS has been made a priority through the establishment of federal budgetary mechanisms specifically for this model and also through initiatives to extend FHS coverage in medium and large urban centers ${ }^{4}$. However, the transition from the former model, represented by traditional health care facilities, over to the FHS is not yet complete in many cities ${ }^{3}$.

The traditional model and the FHS must uphold the SUS principles (provision of universal, equal and integral health care). There are a number of key differences between the two models, including the size of the population covered by each health unit and the structure of health teams. Besides the core team common to both organizational models (general practitioner, nurse, and nurses' aide or licensed practical nurse), the FHS team also has another key professional: the community health worker (CHW). This professional, drawn from the community itself, is responsible for regular home visits, establishing the link between residents and the FHS team, and helping to improve the latter's actions regarding health determinants ${ }^{5}$. 
Numerous benefits of these professionals have been reported, particularly in low-to-middle income countries $^{6}$. With regard to the population served, each FHS team is responsible for 4,000 persons at most versus 12,000 persons / team under the traditional model, in which there must be sufficient CHW to serve $100 \%$ of the registered population. The lower number of individuals covered per team, together with the presence of $\mathrm{CHW}$, brings the FHS closer to its users ${ }^{5}$.

Based on evidence that high-quality PHC may have a positive impact on health indicators $^{7}$, it follows that an innovative PHC model should provide better health outcomes. Comparative performance assessments of the FHS and traditional models by users, health professionals and managers have been carried out ${ }^{8-15}$. Quality-related key elements have been taken as a reference and adapted to the reality of the PHC in Brazil by validation with the Primary Care Assessment Tool (PCATool) ${ }^{7,16-18}$. By estimating indexes, this tool can be used to evaluate the effectiveness of PHC models and further understanding on how health services can facilitate or hinder advances in the quality of care.

We have hypothesized that health professionals would rate FHS more highly than the traditional model, considering the investments of the government to extend the FHS model in Brazil. Thus, the aim of this study was to compare the performance, as assessed by the health professionals, of the two PHC care models in a medium-sized city located in the South-eastern region of Brazil.

\section{METHODS}

\section{STUDY DESIGN}

This was a cross-sectional study conducted to evaluate the performance of the PHC traditional model and FHS within the SUS in Divinópolis city, Minas Gerais state, Brazil, as assessed by health professionals. Additionally, in order to illustrate and complement the data, a description of the appraisal by managers directly involved with the PHC was provided.

This investigation was part of a larger study ${ }^{19}$. The study was approved by the Research Ethics Committees of the Educational Foundation of Divinópolis $(58 / 2009)$ and of the Hospital São João de Deus (22/2011).

\section{LOCAL AND POPULATION}

According to the SUS in Minas Gerais state, each area is divided into health regions, in which one city serves as the reference. In the Mid-western region, Divinópolis is the reference city for higher complexity health actions and the catchment area encompasses 55 neighboring cities and covers an estimated population of $1,198,304$ inhabitants $^{20}$. 
Divinópolis is a medium-sized (213,016 inhabitants, 2011) city. The first PHC facilities were part of the traditional model and implemented in more populous neighborhoods. In 1996, the FHS facilities began to be implemented in rural areas and outlying districts ${ }^{15}$, where health care services were scarcer.

The health system in these regions can be characterized as fragmented with expanding FHS coverage. At the time of the study, the FHS served $27 \%$ of the population and comprised 17 teams, each made up by one general practitioner, one nurse, two nursing assistants and a varying number ( 3 to 11 ) of CHW. The traditional model included 15 PHC facilities. Currently, $51 \%$ of the city's population is covered by the FHS via 32 teams, whereas 11 conventional facilities remain.

For sampling purposes, three health professionals comprising one general practitioner, one nurse and one health assistant (CHW, nurses' aides and licensed practical nurses) from each of the 32 city health facilities from both models were invited to take part in the study. Health facilities with a full complement of health staff (at least one general practitioner, nurse, and health assistant) met the criteria for study eligibility.

Participant selection, based on a list of health professionals provided by the local authorities, was carried out by random sampling. In case of refusal, a second health professional of the same category at the facility was contacted and asked to take part.

The three PHC health managers in the city were also asked to participate. Since the number of managers interviewed was low and the PCATool version designed for managers does not specify the PHC model, the focus of this analysis was merely descriptive.

\section{DATA COLLECTION AND VARIABLES}

Interviews were performed between August and November, 2011. The instrument used was a pre-tested questionnaire that included socio-demographic variables and variables related to the PHC performance. The performance of the PHC was measured by the PCATool designed for managers and health professionals ${ }^{7,16-18}$. It contains approximately 100 questions, divided into eight attributes (accessibility, longitudinality, comprehensiveness, family focus, professional formation, first-contact, coordination and community orientation $\left.^{7-9,12,16,17,21}\right)$, containing a variable number of questions. Within each attribute, respondents must answer on an increasing six-point Likert-type scale ranging from 0 (never) to 5 (always), with the exception of two questions on the accessibility attribute which adopt a decreasing scale and must therefore be converted for analysis. The PHC index (PHCI) was estimated based on the average points obtained for the responses to each attribute (partial PHCI) and to the eight attributes overall (general PHCI). The higher the PHCI, the better the evaluation of PHC performance ${ }^{16}$. PCATool was adapted and translated into Portuguese and exhibited good validity and reliability characteristics in its validation process for use in Brazil ${ }^{16,17}$. Internal consistency measured by Cronbach alpha was $0.60-0.90$ for the eight attributes and 0.60 for the overall scale. Correlation of the items with the overall scale 
was $0.47-0.60^{17}$. Data collection was performed electronically using the Questionnaire Development System $\left(\mathrm{QDS}^{\mathrm{TM}}\right)$, version 2.6.1.

\section{DATA ANALYSIS}

Descriptive analysis was performed by estimating absolute and relative frequencies. PHCI were estimated and compared according to PHC model and health professional categories using Student's t-test. Pearson's Chi-squared test was employed to compare the socio-demographic variables and PHC models.

Univariate polytomous logistic regression was also performed for each PHC attribute. This method is best suited to Likert-type outcome variables containing more than two categories $^{22}$. The highest PHC performance index (always) was compared separately with lower performance indexes never/rarely, sometimes and very often for the PHC models, taking the FHS model as the reference category. Strength of the association was estimated by odds ratios (OR) together with $95 \%$ confidence intervals.

All analyses were performed using Stata software, version 11.0.

\section{RESULTS}

Twenty-one out of the 32 health facilities were included in the study, which together yielded 93 health professionals eligible for the study. One FHS unit located in the rural area was excluded for having an incomplete team of health professionals.

A total of $78(83.9 \%)$ health professionals were interviewed. Losses occurred due to refusal $(n=2)$, maternity leave, absenteeism for health problems $(n=2)$, and non-response after three contact attempts $(n=8)$. No differences in losses for socio-demographic variables were detected between health professionals from the FHS and the traditional models $(\mathrm{p}>0.05)$. Interview duration ranged from 30 to 60 minutes.

Participation of nurses and health assistants in the study was relatively homogenous, whereas a lower participation by general practitioners was observed. Participants were predominantly female and aged 46 years or older. Approximately $41 \%$ of the participants reported having post-graduate level education and $33 \%$ had practiced for 11 years or longer. No differences were found between interviewees from the traditional and FHS models (Table 1).

Table 2 depicts the results on performance of the PHC models according to the health professional category. The three categories rated the FHS model more highly on longitudinality and general PHCI. The FHS performed better for comprehensiveness according to general practitioners and health assistants, whereas nurses and health assistants ascribed higher scores to the FHS for family focus. The attributes community orientation and professional formation achieved higher scores for the FHS than the traditional model according to the health assistants. 
The comparison of indexes between the PHC models showed that the FHS had better performance overall than the traditional model (general PHCI $=3.6$ versus 3.2 ). Longitudinality (PHCI $=4.1$ versus 3.3), comprehensiveness $(\mathrm{PHCI}=4.1$ versus 3.6), family focus ( $\mathrm{PHCI}=4.3$ versus 3.3$)$ and professional formation $(\mathrm{PHCI}=3.4$ versus 2.9$)$ had better results compared to the other attributes (Figure 1). The first-contact attribute received the highest scores irrespective of the PHC model. Poor performance was observed for the accessibility attribute on both models, in which the traditional model had a slightly better rating than the FHS ( $\mathrm{p}>0.05)$.

Table 1. Distribution of socio-demographic variables according to Primary Health Care model.

\begin{tabular}{|l|c|c|c|c|}
\multirow{2}{*}{ Variables } & $\begin{array}{c}\text { FHS } \\
(\mathrm{n}=40)\end{array}$ & $\begin{array}{c}\text { Traditional } \\
(\mathrm{n}=41)\end{array}$ & $\begin{array}{c}\text { Total } \\
(\mathrm{n}=81)\end{array}$ & \multirow{2}{*}{$\mathrm{p}^{*}-$ value $^{\mathrm{a}}$} \\
\cline { 2 - 4 } & $\mathrm{n}(\%)$ & $\mathrm{n}(\%)$ & $\mathrm{n}(\%)$ & \\
\hline
\end{tabular}

Professional categories

\begin{tabular}{|c|c|c|c|c|}
\hline Nurse & $14(32.6)$ & $14(36.8)$ & $28(34.6)$ & \multirow{3}{*}{0.99} \\
\hline Health assistant ${ }^{b}$ & $16(37.2)$ & $15(39.5)$ & $31(38.3)$ & \\
\hline General Practitioner & $13(30.2)$ & $9(23.7)$ & $22(27.2)$ & \\
\hline \multicolumn{5}{|l|}{ Gender } \\
\hline Female & $31(77.5)$ & $29(70.3)$ & $60(74.0)$ & \multirow{2}{*}{0.49} \\
\hline Male & $9(22.5)$ & $12(29.7)$ & $21(26.0)$ & \\
\hline \multicolumn{5}{|l|}{ Age (years) } \\
\hline$\leq 35$ & $18(45.0)$ & $13(31.7)$ & $31(38.2)$ & \multirow{3}{*}{0.22} \\
\hline $36-45$ & $10(25.0)$ & $8(19.6)$ & $18(22.3)$ & \\
\hline$\geq 46$ & $12(30.0)$ & $20(48.7)$ & $32(39.5)$ & \\
\hline \multicolumn{5}{|l|}{ Education } \\
\hline High school & $15(37.5)$ & $15(36.5)$ & $30(37.0)$ & \multirow{3}{*}{0.78} \\
\hline Graduate level & $10(25.0)$ & $8(19.5)$ & $18(22.2)$ & \\
\hline Post-graduate & $15(37.5)$ & $18(44.0)$ & $33(40.8)$ & \\
\hline \multicolumn{5}{|l|}{ Years practicing } \\
\hline$\leq 2$ & $7(17.5)$ & $10(23.3)$ & $17(21.0)$ & \multirow{4}{*}{0.37} \\
\hline $3-5$ & $11(27.5)$ & $9(21.9)$ & $20(24.7)$ & \\
\hline $6-10$ & $11(27.5)$ & $6(14.6)$ & $17(21.0)$ & \\
\hline$\geq 11$ & $11(27.5)$ & $16(40.2)$ & $27(33.3)$ & \\
\hline
\end{tabular}

ap-value obtained by Pearson's Chi-squared test; 'Health assistant: community health workers, nurses' aides and licensed practical nurses. 
Table 2. Comparison of primary health care indexes according to health professional category $(\mathrm{n}=81)$ and $\mathrm{PHC}$ model.

\begin{tabular}{l|c|c|c|c|c|c|c|c|c|}
\hline \multirow{2}{*}{ Attributes } & \multicolumn{7}{|c|}{ Professional category/PHC model } \\
\cline { 2 - 13 } & \multicolumn{3}{|c|}{ Nurse } & \multicolumn{2}{|c}{ General practitioner } & \multicolumn{2}{c}{ Health assistant } \\
\cline { 2 - 12 } & FHS & Trad. & p-value & FHS & Trad. & p-value & FHS & Trad. & p-value \\
\hline Accessibility & 1.8 & 1.9 & 0.29 & 1.6 & 1.7 & 0.36 & 1.6 & 1.7 & 0.18 \\
\hline First-contact & 4.9 & 5.0 & 0.15 & 4.9 & 3.8 & 0.20 & 4.8 & 4.9 & 0.13 \\
\hline Longitudinality & 4.2 & 3.3 & $0.00^{*}$ & 4.1 & 3.7 & $0.09^{*}$ & 4.0 & 3.1 & $0.02^{*}$ \\
\hline Comprehensiveness & 4.0 & 3.7 & 0.06 & 4.1 & 3.7 & $0.04^{*}$ & 4.0 & 3.3 & $0.00^{*}$ \\
\hline Coordination & 3.9 & 3.7 & 0.37 & 3.9 & 3.6 & 0.19 & 3.8 & 3.9 & 0.30 \\
\hline Family focus & 4.3 & 3.3 & $0.00^{*}$ & 4.5 & 3.8 & 0.08 & 4.4 & 2.9 & $0.00^{*}$ \\
\hline Community orientation & 2.5 & 2.6 & 0.35 & 3.0 & 3.4 & 0.15 & 2.9 & 2.2 & $0.02^{*}$ \\
\hline Professional formation & 3.3 & 2.8 & 0.06 & 3.6 & 3.4 & 0.28 & 3.4 & 2.7 & $0.01^{*}$ \\
\hline General & 3.6 & 3.3 & $0.01^{*}$ & 3.7 & 3.4 & $0.04^{*}$ & 3.6 & 3.1 & $0.00^{*}$
\end{tabular}

ap-value obtained by Student's t-test; *statistically significant.

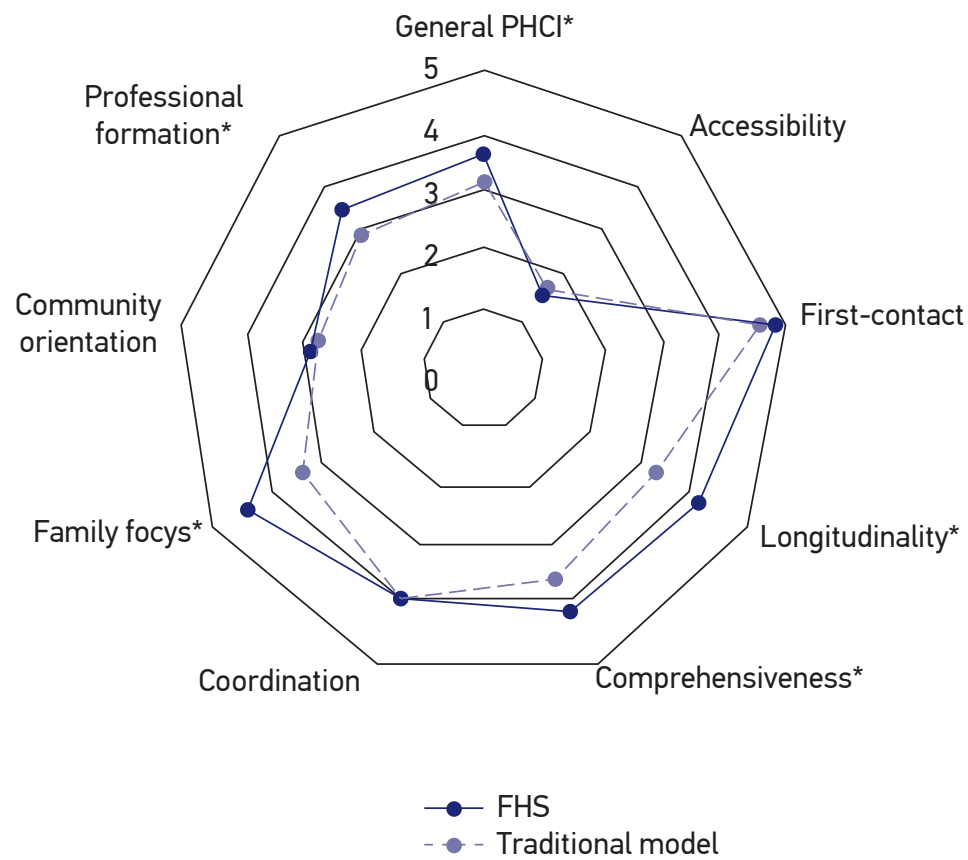

${ }^{*}$ p-value $\leq$ 0.00; FHS: Family Health Strategy; PHCl: Primary Health Care Index.

Figure 1. Primary health care indexes according to health care model $(n=81)$. 
The results of the univariate polytomous logistic regression (Table 3) showed that the traditional model yielded higher OR estimates for longitudinality, comprehensiveness, family focus and professional formation attributes, indicating that the traditional model was associated with a worse performance. For longitudinality, there was a greater likelihood of obtaining a lower performance (sometimes) than higher performance (always) index (OR $=7.6 ; 95 \%$ CI $2.8-20.7)$ under the traditional model. The lowest scored category never/ rarely could not be determined due to the low count distributions found in this category. No differences were detected for the other PHC attributes (data not shown).

Evaluations by health managers revealed a general PHCI $=3.5$, and the following partial PHCI: accessibility $(\mathrm{PHCI}=1.9)$, first contact $(\mathrm{PHCI}=5.0)$, longitudinality $(\mathrm{PHCI}=3.7)$, comprehensiveness $(\mathrm{PHCI}=3.8)$, family focus ( $\mathrm{PHCI}=3.1$ ) professional formation $(\mathrm{PHCI}=3.7)$, coordination $(\mathrm{PHCI}=3.7)$ and community orientation $(\mathrm{PHCI}=3.0)$.

Table 3. Univariate polytomous logistic regression for comparison of Primary Health Care (PHC) performance and care models according to attributes.

\begin{tabular}{|c|c|c|c|}
\hline \multirow[b]{2}{*}{ Attributes } & \multicolumn{3}{|c|}{ PHC performance ${ }^{1}$} \\
\hline & $\begin{array}{c}\text { Never/Rarely }{ }^{2} \\
\text { OR }(95 \% \mathrm{Cl})\end{array}$ & $\begin{array}{l}\text { Sometimes } \\
\text { OR }(95 \% \mathrm{Cl})\end{array}$ & $\begin{array}{l}\text { Very Often } \\
\text { OR }(95 \% \mathrm{Cl})\end{array}$ \\
\hline \multicolumn{4}{|l|}{ Longitudinality } \\
\hline Traditional & Indeterminate & $7.6(2.8-20.7)$ & - \\
\hline FHS & 1.0 & 1.0 & - \\
\hline \multicolumn{4}{|c|}{ Comprehensiveness } \\
\hline Traditional & Indeterminate & $10.0(1.1-94.0)$ & $3.8(1.4-10.0)$ \\
\hline FHS & 1.0 & 1.0 & 1.0 \\
\hline \multicolumn{4}{|l|}{ Family focus } \\
\hline Traditional & Indeterminate & $29.7(3.5-249.7)$ & $3.6(1.2-11.2)$ \\
\hline FHS & 1.0 & 1.0 & 1.0 \\
\hline \multicolumn{4}{|c|}{ Professional formation } \\
\hline Traditional & Indeterminate & $4.7(1.2-18.7)$ & $2.3(0.6-8.7)$ \\
\hline FHS & 1.0 & 1.0 & 1.0 \\
\hline
\end{tabular}

FHS: Family Health Strategy; OR: odds ratio; Cl: confidence interval; ${ }^{1}$ Model separately compared the performance categories never/rarely, sometimes and very often with the category always (best performance) for all attributes, except longitudinality. For longitudinality, very often was taken as reference (best performance) due to absence of data distribution in this category; ${ }^{2}$ Indeterminate: OR could not be obtained for never/rarely due to the small number of observations in this category. 


\section{DISCUSSION}

The present study entailed the analysis of quality-related key elements of PHC within the SUS to compare the performance of the traditional and FHS health care models. The FHS was ranked better overall and attained higher indexes only for four out of the eight attributes. These findings are in line with results of other investigations showing superior performance of the FHS on evaluation by health professionals or users ${ }^{8,10,12-14,23,24}$. The performance of PHC as assessed by managers and health professionals could not be directly compared. However, both are in agreement concerning the poor performance on accessibility and community orientation attributes.

Longitudinality was a highly ranked attribute and possibly one of the main strengths perceived by professionals and also by users. Some studies have shown that professionals tend to rate this attribute higher than users ${ }^{25,26}$, partly because they are responsible for implementing the health services. Other authors ${ }^{27}$ have pointed out the importance of the evaluation of longitudinality and note that positive results should be expected, since it is a central aspect of the Brazilian PHC model. The family focus attribute of the FHS was also ranked highly, representing another category clearly perceived by health professionals and a service essentially centered on family users. Other national investigations have found similar results for longitudinality ${ }^{13}$ and family focus attributes ${ }^{12,13,23,25}$.

The establishment of the FHS model in line with the SUS principles has led to a need for more qualified health professionals. Teams of health professionals from this model are commonly associated with a higher level of training ${ }^{13}$, probably due to the complexity of the activities in routine daily practice ${ }^{28}$. Of note, given the hegemonic nature of the FHS provided for in the Primary Care Plan ${ }^{5}$, heavier investment in training these professionals could be expected. This is the case why the FHS has expanded, with consequent intake of new professionals requiring greater training, and also because these practitioners may face greater demands owing to their closer contact with the community.

Efforts towards training health professionals of the FHS model, particularly health assistants, have been made by the Brazilian Ministry of Health ${ }^{8}$, perhaps explaining the differences observed in evaluations of this attribute by health assistants relative to general practitioners and nurses. Additionally, CHW is a category existing only in the FHS, and they are often responsible for facilitating contact and communication with families, providing information on risk factors, as well as health and social problems of their members ${ }^{2}$. Given that CHW constitute a large, separate category in the FHS, it may be the focus of more training programs. Notably, these professionals have no prior skills to perform the role, so municipal health secretariats are responsible for providing this training.

Our findings concerning the comprehensiveness of PHC were similar to results of other studies $^{12,13,23}$. This finding might stem from the greater effectiveness in provision of health promotion and prevention action by the FHS through programmed service demand prioritizing vulnerable groups, in contrast to the traditional model, which provides these actions mainly in response to spontaneous demand. 
No other advances made by the FHS were evident for the remaining attributes assessed in the study, with the exception of community orientation, which was rated as better by the health assistants (but not by nurses or general practitioners). The PHC models could not be distinguished for their capacity to respond to community needs or to promote community participation in health ${ }^{16}$, demonstrating the ineffectiveness of health practices that are formulated for the community without considering its involvement in health decisions. These problems involving both FHS and traditional model may occur due to their concomitance, which can create a virtual competition or complementarity of the models, hindering the effective exercising of integrality ${ }^{25}$.

The relatively good performance of first-contact, irrespective of care model, should be interpreted with caution, since the results found for this attribute and for accessibility seem to be conflicting. Whereas the first-contact attribute attained a PHCI $>4$, accessibility had the lowest index, particularly under the FHS model. Even after two decades of SUS, which upholds universal access as one of its most important principles, the accessibility attribute was identified as the main shortcoming of the PHC in our study. When access to the services network fails, the PHC cannot play the role of gate-keeper of a universal health system, despite the efforts of professionals in this regard ${ }^{26}$. Thus, the good performance of the first-contact attribute may have been limited those users who actually reached the health facilities, whereas the accessibility attribute evaluated the possibility of actual inclusion in the health system. Preliminary attempts to improve access to PHC services could include extending working time of health facilities as well as that of multi-professional teams, establishing scheduled visits during the weekend, and decentralizing drug dispensing through health facilities. Furthermore, greater virtual communication by phone or e-mail with users should further improve accessibility ${ }^{14,25}$.

The establishment of health systems that act as effective networks is one of the challenges of PHC, in which a number of Brazilian cities have difficulties re-structuring and constituting an effective system of referral and counter-referral ${ }^{12,13}$. The coordination attribute, which denotes continuity of patient care and integration with the other levels of health care ${ }^{5}$, attained low indexes for referral and counter-referral systems, with no differences between the models. Obstacles in referral and counter-referral, along with the different health care levels, could lead to an increase of diseases and their complications, requiring more complex levels of care to treat these cases ${ }^{23}$. The prevalence of $36.7 \%$ hospitalizations for primary care-sensitive conditions was recently estimated for the city ${ }^{19}$. This high rate could be the result of the shortcomings in access to health care and in the referral and counter-referral system, precluding the treatment of health problems that can be prevented when treated by PHC in a timely and effective manner. Furthermore, these results might reflect those users who did not reach PHC as the first-contact, seeking other levels of health care.

In our study, we employed univariate polytomous regression, since it is an appropriate method to be applied to Likert-type outcomes ${ }^{22}$. Despite it, the results emerging from this analysis should be interpreted carefully, because the small sample size led to large confidence intervals. Nevertheless, this analysis yielded similar results to Student's t-test, revealing differences between the PHC models with regard to longitudinality, comprehensiveness, family focus and professional formation. 
Our study revealed key findings, which might support health decision-making within the municipality and neighboring cities in the Mid-western area of Minas Gerais state. These data further contribute to other investigations by our group involving the assessment of PHC users who were hospitalized for ambulatory care-sensitive conditions ${ }^{15,29}$. We should note, however, that some results probably cannot be extrapolated to other Brazilian cities given differences in health professional perceptions as well as disparities in characteristics of local health systems. In addition, changes occurring in health professional staff or in the PCATool over time could compromise our findings. Despite these limitations, we believe that our results are valid, since the concomitance of two PHC models operating in Divinópolis, as well as in many other Brazilian regions, remains ${ }^{25,26}$.

In view of this, continuous assessment of PHC must be carried out to inform decision-making by professionals and managers, highlighting the strengths and weaknesses of each PHC model. Other tools besides the PCATool which is best suited for the Primary Care Plan Proposa ${ }^{18,30}$ can be considered adequate for performing quality analysis of a host of different aspects (economic, services, social support), as it is the case of the National Program for Access and Quality Improvement in Primary Care (PMAQ) ${ }^{31}$.

The city has been unable to attain the high level of FHS performance. Difficulties in establishing the FHS in medium-to-large cities on a national scale have been noted, in part due to the high demographic density and rapid evolution and development of medical technologies ${ }^{13,32}$. Despite the autonomy of the city analyzed concerning planning and managing financial resources destined for public health care, the establishment of the FHS in Divinópolis has developed very slowly, achieving a modest growth of about $7.0 \%$ since the early 2000s. From the beginning of the study until now, FHS coverage has increased along with the workload within strategic traditional units.

\section{CONCLUSIONS}

This study, taken together with data on coverage of the FHS model in the city, highlights that increased FHS coverage should be accompanied by improvement in the quality of FHS facilities available. Provision of regular financial and human resources will be crucial to allow replacement of the traditional model as opposed to the FHS remaining an alternative PHC model in Brazilian cities. The FHS should be able to act as the gatekeeper of SUS, facilitate patient access to health services, and coordinate care across the different levels of the health system, thereby catering for community needs.

\section{ACKNOWLEDGMENTS}

The authors gratefully acknowledge the Municipal Secretary of Health of Divinópolis, MG, health managers and health professionals for making themselves available for the study. The authors would also like to thank Prof. MD. Aline Lopes, of the Federal University of Minas Gerais (UFMG), for the valuable critical appraisal of the manuscript. 


\section{REFERENCES}

1. Caldeira AP, Fernandes VB, Fonseca WP, Faria AA. Internações pediátricas por condições sensíveis à atenção primária em Montes Claros, Minas Gerais, Brasil. Rev Bras Saude Mater Infant 2011; 11(1): 61-71. DOI: $10.1590 /$ S1519-38292011000100007

2. Escorel S, Giovanella L, Mendonça MH, Senna MC. O Programa de Saúde da Família e a construção de um novo modelo para a atenção básica no Brasil. Rev Panam Salud Publica 2007; 21(2-3): 164-76. DOI.10.1590/ S1020-49892007000200011

3. Giovanella L, Mendonca MH, Almeida PF, Escorel S, Senna MC, Fausto MC, et al. Saúde da família: limites e possibilidades para uma abordagem integral de atenção primária à saúde no Brasil. Cien Saúde Coletiva 2009; 14(3): 783-94. DOI. 10.1590/ S1413-81232009000300014

4. Machado CV, Lima LD, Viana LS. configuração da atenção básica e do programa saúde da familia em grandes municípios do Rio de Janeiro, Brasil. Cad Saúde Pública 2008; 24(1): s42-57. DOI. 10.1590/ S0102-311X2008001300010

5. Brasil. Ministério da Saúde. Política Nacional de Atenção Básica. Secretaria de Atenção à Saúde. Departamento de Atenção Básica. Série E. Legislação em Saúde. Brasília: 2012. [Internet]. Disponível em: http:/ / 189.28.128.100/ dab/docs/publicacoes/geral/pnab.pdf (Acessado em 2 de outubro de 2016).

6. Pallas SW, Minhas D, Perez-Escamilla R, Taylor L, Curry L, Bradley EH. Community health workers in low- and middle-income countries: what do we know about scaling up and sustainability? Am J Public Health 2013; 103(7): e74-82. DOI. 10.2105/ AJPH.2012.301102

7. Starfield B. Atenção primária: equilíbrio entre necessidades de saúde, serviços e tecnologia. Tradução: Fidelity Translations. UNESCO. Ministério da Saúde 2002: 726 .

8. Albuquerque FJ, Melo CF, Souza Filho FE, Araújo Neto JL. Avaliação da estratégia saúde da família a partir das crenças dos profissionais. Estud Psicol 2011; 28(3): 363-70. DOI. 10.1590/S0103-166X2011000300008

9. Bosi ML, Pontes RJ, Vasconcelos SM. Dimensões da qualidade na avaliação em saúde: concepções de gestores. Rev Saúde Pública 2010; 44(2): 318-24. DOI. 10.1590/S0034-89102010000200012

10. Castro RC, Knauth DR, Harzheim E, Hauser L, Duncan BB. Avaliação da qualidade da atenção primária pelos profissionais de saúde: comparação entre diferentes tipos de serviços. Cad Saúde Pública 2012; 28(9): 177284. DOI. 10.1590/S0102-311X2012000900015
11. Elias PE, Ferreira CW, Alves MC, Cohn A, Kishima V, Junior AE, et al. Atenção básica em saúde: comparação entre PSF e UBS por estrato de exclusão social no município de São Paulo. Cien Saúde Coletiva 2006; 11(3): 633-41. DOI. 10.1590/S1413-81232006000300012

12. Ibañez N, Rocha JS, Castro PC, Ribeiro MC, Forster AC, Novaes MH, et al. Avaliação do desempenho da atenção básica no Estado de São Paulo. Cien Saúde Coletiva 2006; 11(3): 683-703.

13. Stralen CJ, Belisario SA, Stralen TB, Lima AM, Massote AW, Oliveira CL. Percepção dos usuários e profissionais de saúde sobre atenção básica: comparação entre unidades com e sem saúde da família na Região CentroOeste do Brasil. Cad Saúde Pública 2008; 24(1): s14858. DOI. 10.1590/S0102-311X2008001300019

14. Silva SA, Nogueira DA, Paraizo CM, Fracolli LA. Avaliação da atenção primária à saúde: visão dos profissionais de saúde. Rev Esc Enferm USP. 2014; 48(spe): 122-8. DOI: 10.1590/S0080-623420140000600018

15. Sá FS, Oliveira CL, Fernandino DD, Menezes de Pádua CA, Cardoso CS. Assessment of primary health care from the perspective of patients hospitalized for ambulatory care sensitive conditions. Fam Pract 2016; 33(3): 243-8. DOI: 10.1093/fampra/cmv096

16. Macinko J, Almeida C, de Sá PK. A rapid assessment methodology for the evaluation of primary care organization and performance in Brazil. Health Policy Plan 2007; 22(3): 167-77. DOI. 10.1093/heapol/czm008

17. Almeida C, Macinko J. Validação de uma metodologia de avaliação rápida das características organizacionais e do desempenho dos serviços de atenção básica do sistema de saúde (SUS) em nível local. Organização Pan-Americana da Saúde. Brasília 2006: 215.

18. Harzheim E, Oliveira MM, Agostinho MR, Hauser L, Stein AT, Gonçalves MR, et al. Validação do instrumento de avaliação da atenção primária à saúde: PCAToolBrasil adultos. Rev Bras Med Fam Comunidade 2013; 8(29): 274-84.

19. Cardoso CS, Pádua CM, Rodrigues-Júnior AA, Guimarães DA, Carvalho SF, Valentin RF, et al. Contribuição das internações por condições sensíveis à atenção primária no perfil das admissões pelo sistema público de saúde. Rev Panam Salud Publica 2013; 34(4): 227-34.

20. Malachias I, Leles FA, Pinto MA. Plano Diretor de Regionalização da saúde de Minas Gerais. Belo Horizonte: Secretaria de Estado de Saúde de Minas Gerais; 2010. 264 p.

21. Macinko J, Montenegro H, Adell CN, Etienne C. La renovación de la atención primaria de salud en las Américas. Rev Panam Salud Publica 2007; 21(2/3): 73-84. 
22. Hosmer DW, Lemeshow S, Sturdivant R. Logistic regression models for multinomial and ordinal outcomes in: Applied Logistic Regression. New York: Wiley 2013; 269-312. DOI. 10.1002/9781118548387.ch8

23. Elias E, Magajewski F. A Atenção primária à saúde no sul de santa catarina: uma análise das internações por condições sensíveis à atenção ambulatorial, no período de 1999 a 2004. Rev Bras Epidemiol 2008; 11(4): 633-47. DOI. 10.1590/S1415-790X2008000400011

24. Lima EF, Sousa AI, Leite FM, Lima RC, Souza MH, Primo CC. Avaliação da Estratégia Saúde da Família na Perspectiva dos Profissionais de Saúde. Esc Anna Nery 2016; 20(2): 275-80. DOI. $10.5935 / 1414-8145.20160037$

25. Silva SA, Baitelo TC, Fracolli LA. Avaliação da atenção primária à saúde: a visão de usuários $\mathrm{e}$ profissionais sobre a estratégia de saúde da família. Rev Latino-Am Enfermagem 2015; 23(5): 979-87. DOI: 10.1590/0104-1169.0489.2639

26. Araújo RL, Mendonça AV, Sousa MF. Percepção dos usuários e profissionais de saúde no Distrito Federal: os atributos da atenção primária. Saúde Debate 2015; 39(105): 387-99. DOI. 10.1590/0103-110420151050002007

27. Cunha EM, Giovanella L. Longitudinalidade/ continuidade do cuidado: identificando dimensões e variáveis para a avaliação da atenção primária no contexto do sistema público de saúde brasileiro. Ciên Saúde Coletiva 2011; 16(1): 1029-42. DOI. 10.1590/ S1413-81232011000700036
28. Leão CD, Caldeira AP. Avaliação da associação entre qualificação de médicos e enfermeiros em atenção primária em saúde e qualidade da atenção. Ciên Saúde Coletiva 2011; 16(11): 4415-23. DOI. 10.1590/S1413-81232011001200014

29. Pereira ML, Acurcio FA, Menezes de Pádua CA. Evaluation of primary health care by users and nonusers of drugs hospitalized for primary care-sensitive conditions. Aten Primaria 2016; 49(4): 258-60. DOI: 10.1016/j.aprim.2016.06.006

30. Fracolli LA, Gomes MF, Nabão FR, Santos MS, Cappellini VK, Almeida AC. Instrumentos de avaliação da atenção primária à saúde: revisão de literatura e metassíntese. Ciên Saúde Coletiva 2014; 19(12): 485160. DOI. 10.1590/1413-812320141912.00572014

31. Brasil. Ministério da Saúde. Secretaria de Atenção à Saúde. Programa nacional de melhoria do acesso e da qualidade da atenção básica (PMAQ): manual instrutivo. Departamento de Atenção Básica 2012. Brasília 2012. [Internet]. Disponível em: http:/ / dab.saude.gov.br/ portaldab/biblioteca.php?conteudo=publicacoes / pmaq (Acessado em 15 de janeiro de 2017).

32. Almeida PF, Giovanella L, Mendonça MH, Escorel S. Desafios à coordenação dos cuidados em saúde: estratégias de integração entre níveis assistenciais em grandes centros urbanos. Cad Saúde Pública 2010; 26(2): 286-98. DOI. 10.1590/S0102-311X2010000200008

Received on: 11/01/2016

Final version presented on: 02/11/2017

Accepted on: 05/18/2017 